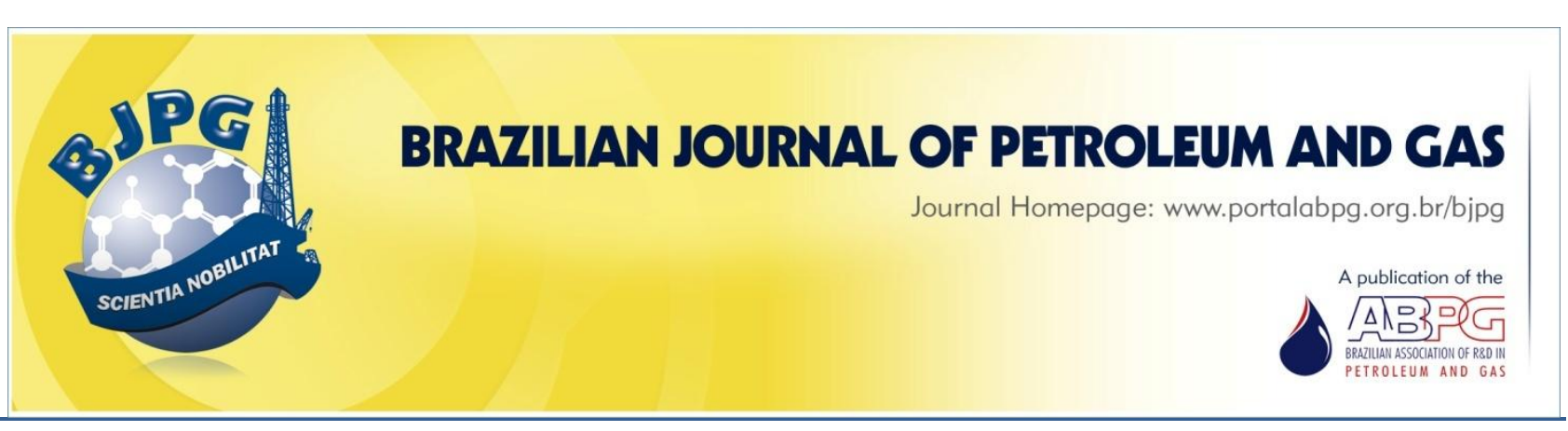

\title{
OPTIMIZATION FOR DRILLING SCHEDULE OF WELLS IN THE DEVELOPMENT OF HEAVY OIL RESERVOIRS
}

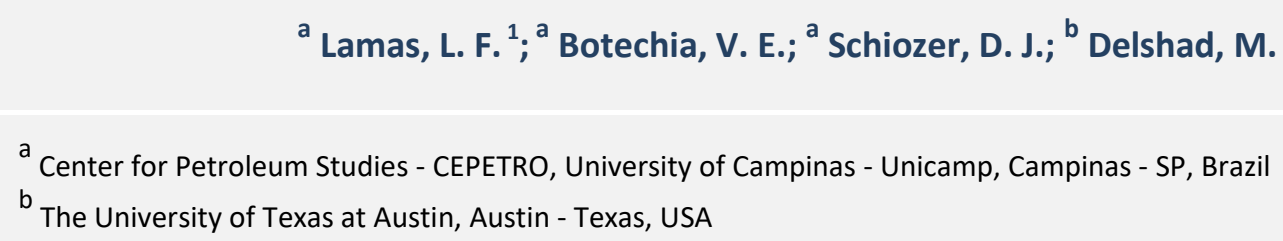

Received: 30.06.2017 / Revised: 13.08.2017 / Accepted: 25.08.2017 / Published on line: 16.10.2017

\begin{abstract}
During the development stage of a petroleum field, one important decision is to define the schedule for drilling the wells. Several general rules were listed for light and heavy oils. However, these rules are not always applicable and it may be important to use simulation models to test and choose the schedule. This paper consists of the development, implementation, and application of two different algorithms for optimization of wells drilling schedule. The first algorithm seeks, for each period, which well brings the best economic output. Once this well is selected, the second period of time is tested considering the remaining wells and this procedure is repeated until the last well. The second procedure is based on the reduction of search space where random schedules are generated and the best results maintained for the subsequent generation of scenarios, only allowing the wells to be drilled in the period that produced the best values of the objective function in the previous step. This procedure is repeated until each well converges to the period that results in the best economic return. Both algorithms were tested in two synthetic fields, based on the characteristics of offshore heavy oil and high average permeability reservoirs. To generate a benchmark for the solutions, a large amount of random schedules were tested and a normal distribution for net present values was generated. Both algorithms can be applied in any type of reservoirs, resulting in a very time consuming process in the cases where simulation time is very high. The results from both algorithms lead to net present values higher than at least $95 \%$ of the values from random schedules. For both cases, economic results were significantly better than those found for selecting strategy using wells ranking based in economic indicators, which is a common procedure. Both algorithms are also easy to implement and they can be inserted in a cycle of automated or assisted optimization process.
\end{abstract}

\section{KEYWORDS}

reservoir simulation; production strategy selection; heavy oils

\footnotetext{
${ }^{1}$ To whom all correspondence should be addressed.

Address: Center for Petroleum Studies - CEPETRO, University of Campinas - Unicamp, Campinas - SP, Brazil. ZIP Code: 13083-970 | Phone/Fax: +55 (19) 3521-4664 / +55 (19) 3521-1188 |e-mail: lamas@dep.fem.unicamp.br doi:10.5419/bjpg2017-0014
} 


\section{INTRODUCTION}

Selection of production strategy is a very important step during the process of petroleum field development. This step aims to maximize the values of an objective function (usually net present value) of the project. It consists on the optimization of several variables regarding to number and position of wells, platform size, control values, and others. Drilling and completion of wells is a time consuming operation that demands the use of special equipment such as drilling rigs, PLSVs (Pipe Laying Support Vessel), which may limit the perforation time.

Schiozer et al. (2015) presented a detailed procedure to perform closed loop reservoir management, and its application to decision analysis. One important step of this methodology is the probabilistic optimization, where the authors suggest the selection of representative models and subsequent deterministic strategy selection for each of the selected models.

Gaspar et al. (2016) proposed a methodology that hierarchizes parameters for the production strategy selection, dividing into a group of design variables (G1), control variables (G2), and potential improvement variables (G3).

The group $\mathrm{G} 1$ involves variables that must be selected before the development stage begins. Typically this group encloses number and location of wells, drilling schedule, and platform production and injection limits. Different methodologies can be applied for the optimization of each group separately.

Ravagnani et al. (2011) proposed some economic indicators to compare performance of wells and its use in the process of production strategy selection. Economic indices are defined as producer well economic index (PWEI, Equation 1). It takes into account costs and revenues for individual producers, the injector well economic index (IWEI, Equation 2), and the cost for individual injectors.

$$
P W E I=\sum_{i=0}^{n} \frac{R o_{i}-C o_{i}-C w_{i}-I n v_{w e l l}}{(1+r)^{t_{i}}}
$$

$$
I W E I=\sum_{i=0}^{n} \frac{\operatorname{Cinj}_{i}+I n v_{\text {well }}}{(1+r)^{t_{i}}}
$$

For each well, PWEI or IWEI is calculated. These values are, then, ranked; and simplified sequences ( 2 producers and 1 injector, for example) are defined for drilling sequence.

Andrade Filho (1994) proposed a methodology that uses the polytope search method, which is a direct method for searching the optimum value. This procedure, however, demands high computational efforts, and could be replaced by the plotting of the whole response surface.

Beckner and Song (1995) presented an algorithm based on the problem known as the "travelling salesman" to address the problem of position and drilling schedule for wells. An average interval of three months is considered for drilling wells. They concluded that for heterogeneous reservoirs, there is a significant impact on these parameters due to the cost of wells variable.

Leeuwenburgh et al. (2016) presented a methodology to optimize well drilling schedule (sequence and time) under uncertainty. They observed that solutions tend to be sensitive to the choice of initial control variables values. They also discovered the possibility of obtaining a large number of solutions with very similar results.

Lamas and Schiozer (2016) showed that, for heavy and viscous oils, the selection of drilling schedule based on the ranking of economic indicators leads to sub-optimal values of net present values. This is an indication that, for this type of oil, selection of drilling schedule has a higher impact than for the cases of light oils. Lamas (2014) showed that for heavy oils, due to a slower decrease in reservoir initial pressure, optimized strategies tend to open producers in earlier times than injectors.

Botechia (2016) applied the methodology proposed by Gaspar et al. (2016) to a field with heavy viscous oil to compare the injection of water and polymer as enhanced oil recovery mechanism. The author divided the optimization of $\mathrm{G} 1$ variables into two sub-groups, G1A (number and location of wells, capacity of production systems) and G1B (Drilling Schedule of Wells). This subdivision is practical, because allows the use of different methodologies to optimize each sub-group separately. 
This work focuses on the development and comparison of different methodologies for optimization of drilling schedule of wells for heavy oil fields. The advantage of this methodology, when compared with others found in literature, is that both of them are simple to implement and can be inserted in an optimization procedure, such as the proposed by Gaspar et al. (2016), and in a probabilistic decision analysis, such as the one proposed by Schiozer et al. (2015).

The objective function used in this work is the Net Present Value (NPV), which is the sum of cash flows for every period of a field's life, brought to present time by a discount rate. One of the economic indicators used in the development of algorithms is the Field Economic Indicator (FEI), which is calculated using a similar equation of NPV. The main difference between them is that FEI considers that all wells are opened at the same time, which is unrealistic. This adjustment is made to have a proper comparison regarding the performance of the wells.

The objective of this work is the development, implementation and application of two different algorithms in the optimization a wells' drilling schedule, comparing results from both of them with the methodology proposed by Ravagnani et al. (2011) and with random schedules. Both methodologies need to be robust, demand few simulations, and have the possibility of being automated. These conditions will make it possible for it to be inserted in a hierarchical optimization procedure, such as the one proposed by Gaspar et al. (2016), and used in a probabilistic decision analysis, such as the one discussed by SCHIOZER et al. (2015).

\section{METHODOLOGY}

The first algorithm proposed in this work is based in the search, in each period of the field development, for the well that offers the best economic output. Once this well is selected, the second period of time is tested for the remaining wells. This procedure is repeated until reaching the last well.

The second procedure is based on the reduction of search space. Random schedules are generated and a percentage of the best results are analyzed.
Search space is reduced to prioritize, for each well, the months that resulted in better NPVs. New random schedules are generated, but now allowing only combinations that previously resulted in better results. The procedure is repeated until convergence is achieved.

Using MATLAB, random sequences are generated for opening the wells. This step ensures that all wells are open only one time. This is possible by generating one vector of integers ranging from one to the number of wells, and randomly scrambling this vector. Each random vector is checked for its uniqueness, and stored in a table. In the sequence, for each vector inside this table, a simulation file is generated and simulated.

For each field, a schedule is selected using the methodology proposed by Ravagnani et al. (2011). In this step, field is simulated considering the opening of all wells in the first day of simulation. Values of PWEI and IWEI are calculated, using Equations 1 and 2 . In the sequence, wells are ranked using these indicators, and, then, a sequence considering 2 producers and 1 injector is selected.

Following, values found in both algorithms are compared with values found from ranking of wells indicators, as proposed by Ravagnani et al. (2011), and with a large number of random sequences.

\subsection{Algorithm 1}

The first algorithm consists in the selection, period by period (i.e. month, quarter, semester), of the well with better economic results. To do so, in the first period, $\mathrm{N}$ simulation files are generated $(\mathrm{N}$ is the number of wells), where in each simulation file, a different well is allocated in this period. The remaining wells are allocated in the next period of time. Supposing a hypothetical example of four wells, initially four simulation files are generated, according to Figure 1.

After generation and simulation of these files, Field Economic Indicator (FEI) is calculated for each of them, using Equation 3:

$F E I=\sum_{i=1}^{n} \frac{C F_{i}}{(1+r)^{t_{i}}}$ 


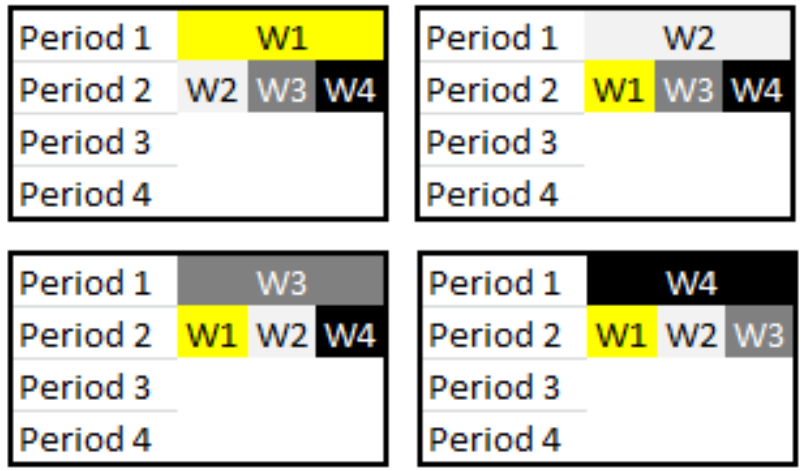

Figure 1. For a hypothetical case of four wells $(\mathrm{Wn})$, four simulation files are generated, where in the first period of time different wells are allocated in each simulation file, and the remaining wells are allocated in the second period of time.

Although FEI and NPV are calculated with very similar equations, they do not have the same meaning. FEl considers that more than one well can be perforated in the same period of time, and because of that, it is unrealistic. This is an important economic indicator and can be used when comparing strategies, but does not reflect realistic values, as NPV does.

Supposing that, for this hypothetical case, W3 resulted in a better FEI, this well will be fixed in the first period, and the process is repeated for the second period. Three simulation files are generated, considering W3 in first period; W1, W2 or W4 in second period; and remaining wells placed in third period. Figure 2 illustrates this situation.

This procedure is repeated until last well is placed in correspondent period. Total number of simulations for this case can be calculated using Equation 4. Parallel computing is used to simulate files in each iteration. A total of N-1 iterations are required to finish the process.

$$
\#_{\text {sim }}=\sum_{i=2}^{N_{\text {wells }}} i
$$

\subsection{Algorithm 2}

The second procedure is based in an evolutionary algorithm. In the first iterations, random sequences of drilling are generated. For each file, NPV is calculated, and for each period, the wells that lead to worse economic scenarios are removed (domain restriction).

With this new domain, new pseudo-random sequences are generated. This process is repeated until convergence is achieved. Convergence may be defined as when, for each well, only one period is allowed for it to be opened. This criterion can be changed, however, in some cases an excessive number of simulations are required. Figure 3 shows this procedure.

To exemplify the implementation of Algorithm 2 , one can imagine an example of reservoir with five wells. Initially, random schedules are generated, and each well can be opened in any of

\begin{tabular}{|c|c|}
\hline Period 1 & W3 - Fixed \\
\hline Period 2 & W1 \\
\hline Period 3 & W2 \\
\hline Peri & \\
\hline
\end{tabular}

\begin{tabular}{|l|l|l|}
\hline Period 1 & \multicolumn{2}{|c|}{ W3 - Fixed } \\
Period 2 & \multicolumn{2}{|c|}{ W2 } \\
\hline Period 3 & W1 & W4 \\
\hline Period 4 & \multicolumn{1}{|l}{} \\
\hline
\end{tabular}

\begin{tabular}{|l|ll|}
\hline Period 1 & \multicolumn{2}{|c|}{ W3 - Fixed } \\
\hline Period 2 & \multicolumn{2}{|c|}{ W4 } \\
\hline Period 3 & W1 & W2 \\
Period 4 & & \\
\hline
\end{tabular}

Figure 2. Simulation files generated to verify the well which generates better economic results when placed in the second period, having well for first period already fixed. 


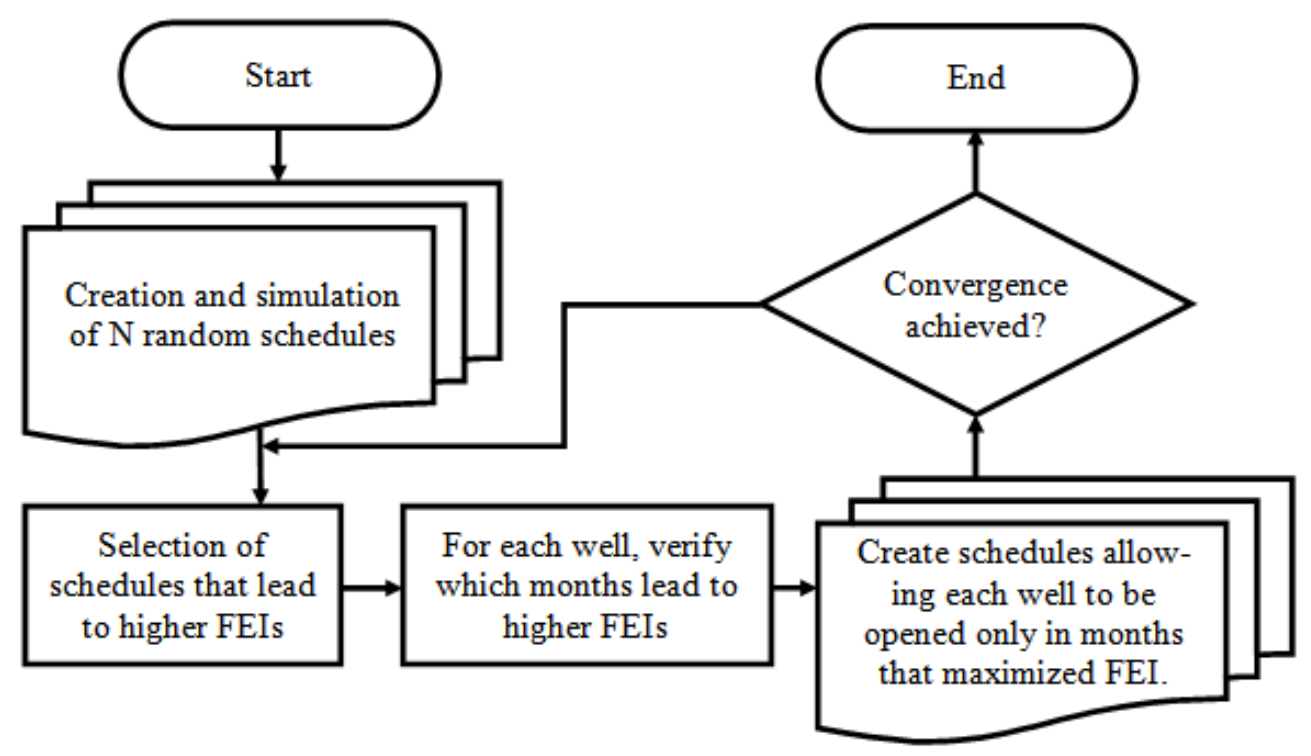

Figure 3. Flow chart for execution of Algorithm 2.
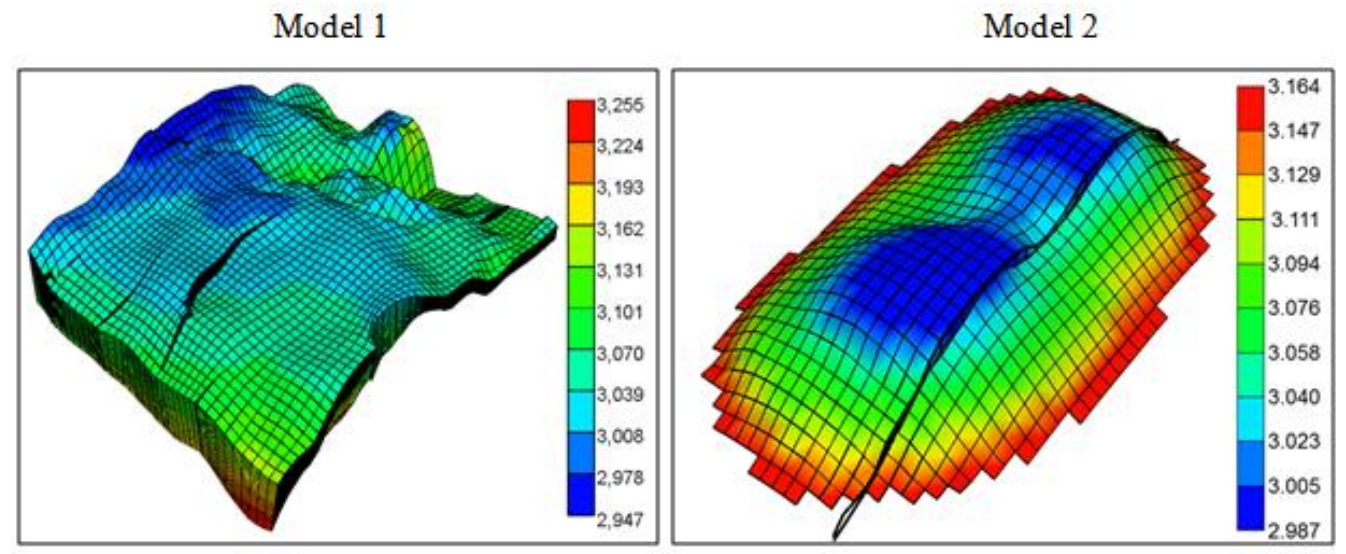

Figure 4. Top grid maps for Model 1 (left) and Model 2 (right).

the five available periods. For each of these random schedules, $\mathrm{FEI}$ is calculated. Table 1 shows an example of schedules and FEl's found at this step.

For this example, the next step would be the generation of pseudo-random schedules, allowing for Well 1 to be open only in the periods 2, 3, and 4; and Well 2 only in periods 1, 2, and 3 . The analysis is repeated for all wells.

The number of schedules generated for each iteration must be adjusted to maximize the use of parallelization resources. The total number of runs depends on model parameters, area and number of blocks, heterogeneity, and number of wells. An initial guess can also help to accelerate the process of convergence. In the tests in this paper, however, no initial guess has been considered.

\subsection{Application}

The methodology was applied in two synthetic field models, with characteristics based on real fields, both with high average permeability and heavy oil. Figure 4 shows maps for the top of each

Table 1. Example of random schedules and FEI calculated to illustrate Algorithm 2.

\begin{tabular}{cccccc}
\hline Well 1 & Well 2 & Well 3 & Well 4 & Well 5 & FEI (EO6 USD) \\
\hline 4 & 2 & 1 & 3 & 5 & 1.47 \\
3 & 1 & 2 & 5 & 4 & 1.44 \\
2 & 3 & 4 & 1 & 5 & 1.42 \\
\hline
\end{tabular}


Table 2. Information of fields studied.

\begin{tabular}{ccc}
\hline Field & Model 1 & Model 2 \\
\hline Blocks (I, J, K) & $37 \times 48 \times 19$ & $24 \times 35 \times 4$ \\
& (28998 active blocks) & (2640 active blocks) \\
Number of Wells & 11 producers, 7 injectors & 25 producers, 12 injector \\
Permeability (mD) & (All horizontal) & (All vertical) \\
Porosity (\%) & 0 to 3200 (mean 1650) & 1568 to 8878 (mean 3681) \\
Temperature ( $\left.{ }^{\circ} \mathrm{C}\right)$ & 1.2 to 31 (mean 20) & 29 to 33 (mean 30) \\
Initial Pressure (MPa) & 81 & 23.4 \\
Dykstra-Parsons Coefficient & 31.7 & 0.3794 \\
Average Oil Viscosity (cP) & 0.3898 & 163 \\
Oil API & 70 & 14 \\
\hline
\end{tabular}

reservoir, and Table 2 shows additional information of the fields.

Using MATLAB, 2000 random sequences were generated for opening the wells. This step ensures that all wells would be opened, and no wells would be opened twice. These random values were used to compare with other methods.

About wells operational constraints, it was considered that each well was working on its maximum physical limits, so production systems and reservoir would not be damaged. Production and injection rate was of $3000 \mathrm{~m}^{3} /$ day, producers minimum BHP of $6000 \mathrm{kPa}$, and injectors maximum BHP of $28000 \mathrm{kPa}$.

\section{RESULTS AND DISCUSSIONS}

For both fields, it was found a normal NPV distribution for the 2000 random sequences. With these values it was possible to draw a Gaussian curve for each field, giving a good basis for comparison with other methods.

Figure 5 shows evolution of maximum, minimum, and average values with different number of realizations for Model 1. Average value remains nearly constant, but limit values (maximum and minimum) tend to grow (maximum values) or decrease (minimum values) when sample increases.

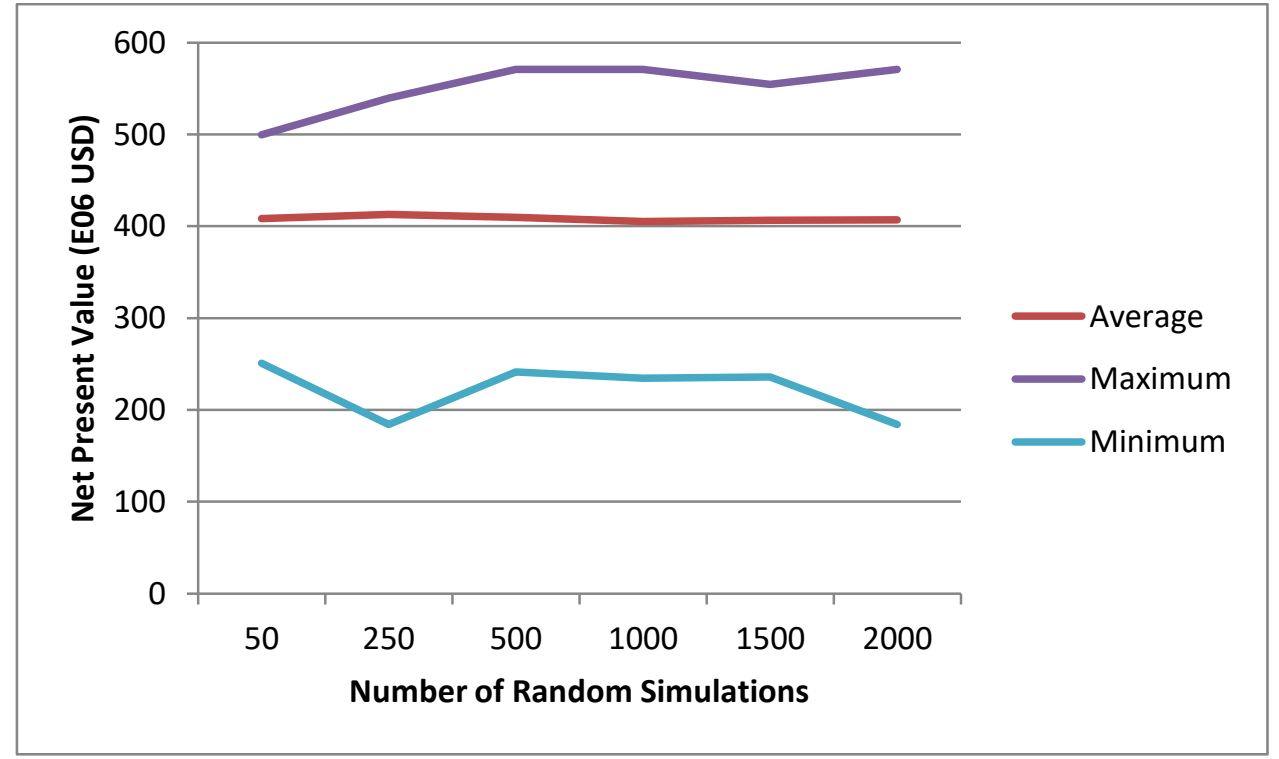

Figure 5. Evolution of average, maximum and minimum values, in Model 1, for different number of random simulations. 


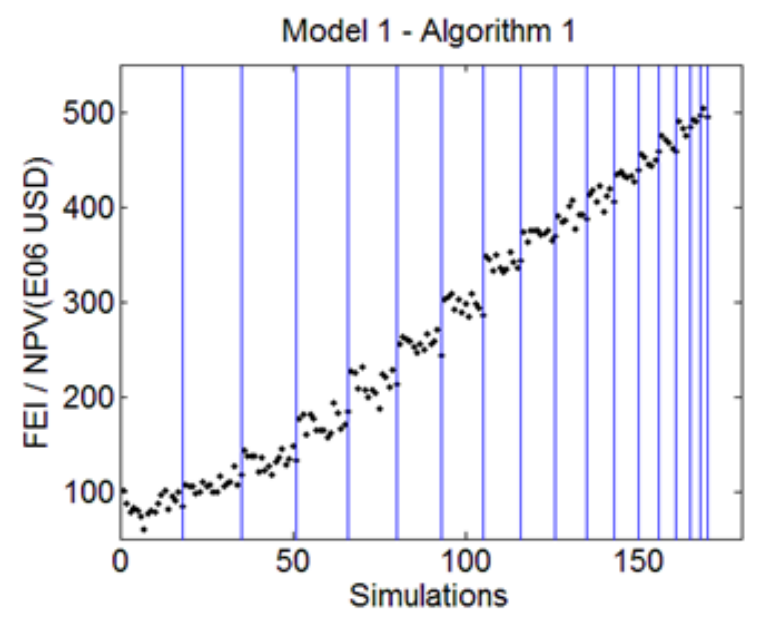

(a)

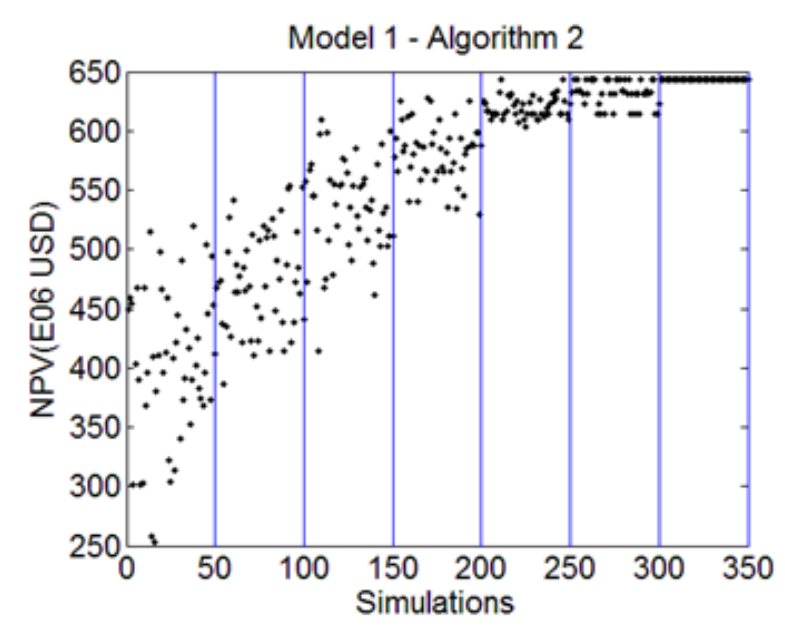

(b)

Figure 6. Evolution of economic indicators during optimization processes, in Model 1, considering algorithm 1 (a) and algorithm 2 (b).

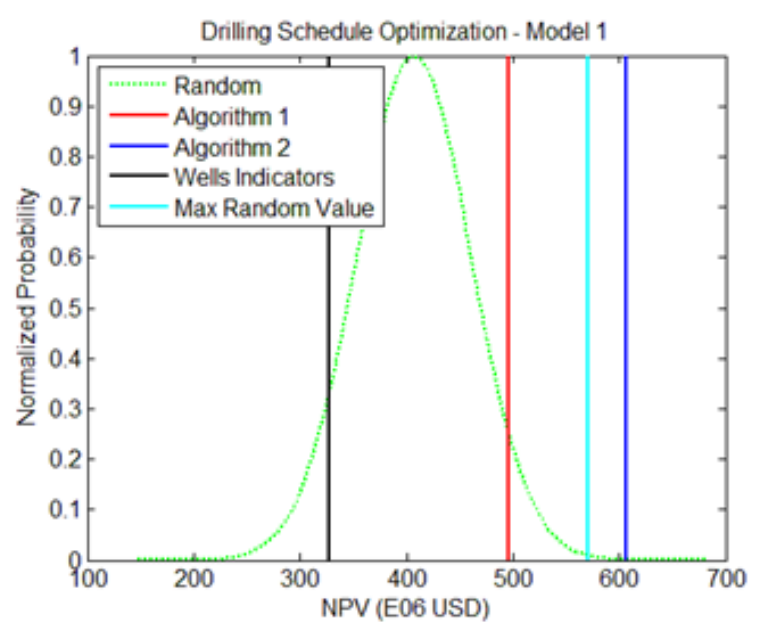

(a)

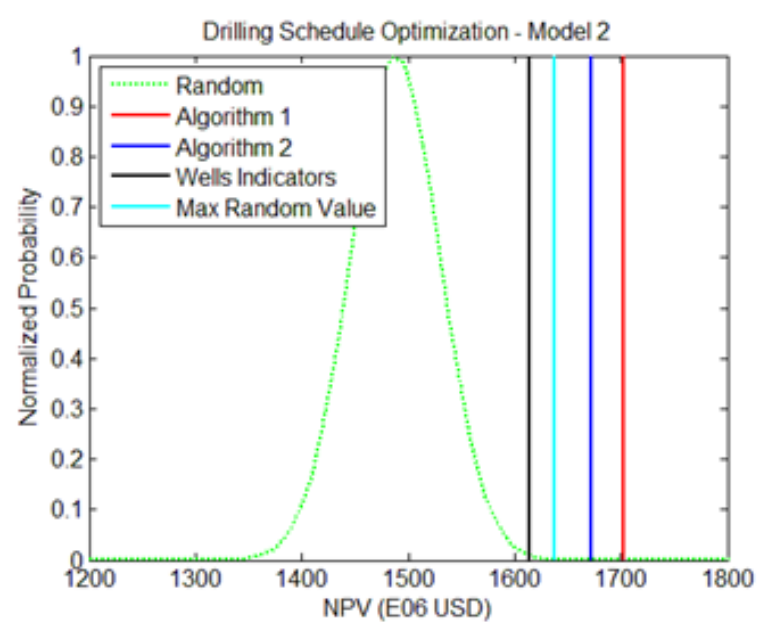

(b)

Figure 7. Results obtained with Algorithm 1, Algorithm 2, and Ranking of wells indicators (Ravagnani, 2011), compared with Gaussian distribution generated with random schedules for Model 1 (a) and Model 2 (b).

Figure 6 shows the evolution of Field Economic Indicator (FEI) and Net Present Value (NPV) during the optimization process using algorithms 1 and 2 for Model 1. Vertical lines separate iterations.

In the case of Algorithm 1, the number of simulations decreases in each iteration. One can also observe that FEI increases during the whole process. The optimum NPV for this case is found in the last iteration, where there are only two options of wells to be opened in the last period of time. It is also important to stress that maximum NPV may be smaller than some previous FEl. At this point, is necessary to remember, then, that FEI considers that more than one well can be drilled in the same period of time, which is not feasible, and because of that, NPV value should be considered.

For the case of Algorithm 2, number of simulations for iteration is constant. It is possible to observe a progressive increase in average NPV, resulted from domain restriction, characteristic of this method.

Figure 7 shows values obtained for both models comparing values obtained with algorithm 1, algorithm 2, wells ranking based on individual economic indicators (Ravagnani et al. 2011), and Gaussian distribution generated for the 2000 random schedules. Table 3 shows details of these results. 
Table 3. Comparison of results for both algorithms.

\begin{tabular}{ccccc} 
& \multicolumn{2}{c}{ Model 1 } & \multicolumn{2}{c}{ Model 2 } \\
& NPV (E09 USD) & \# of Simulations & NPV (E06 USD) & \# of Simulations \\
\hline Normal & 184 to 570 (mean & - & 1.37 to 1.64 (mean & - \\
Distribution & 407 ) & 1 & $1.49)$ & 1 \\
IWEI/PWEI Ranked & 327 & 170 & 1.61 & 702 \\
Algorithm 1 & 495 & 350 & 1.70 & 550 \\
Algorithm 2 & 607 & 1.67 & \\
\hline
\end{tabular}

\section{CONCLUSIONS}

This paper describes the implementation of two different algorithms for optimization of the drilling schedule, and compares the results with other methodologies found in literature. In this section, the main conclusions are discussed.

- For both cases, both algorithms led to higher values of NPV or near the maximum value found for random simulations. It is important to notice that random schedules resulted in a broad range of NPV, but demanded a high number of simulations.

- Both algorithms proposed in this paper resulted in NPVs higher than that found with simple ranking of wells indicators (Gaspar et al., 2016). This is an indication that, for heavy oil reservoirs, the drilling schedule can be important and must be optimized.

- The execution of both algorithms demanded a high number of simulations. When conducting these simulations is not feasible, it is recommended to simulate a small number of random schedules and pick the highest value of NPV. This is because, for both cases, the highest value from the random schedules found, even from small number of realizations, was higher than that found for ranking of wells indicators.

- Algorithm 1 is more advantageous for cases with small number of wells, because it requires fewer simulations. Also, this algorithm allows estimating the total number of simulations demanded, using Equations 1 and 2.

- When the number of wells is high, algorithm 2 is more advantageous because it requires fewer simulations than algorithm 1 .

\section{ACKNOWLEDGEMENTS}

The authors would like to thank Petrobras, Statoil, and FCMG (CMG Reservoir Simulation Foundation). They also would like to thank CAPES (Coordination for the Improvement of Higher Education Personnel) for financial support under process BEX 10004/14-9, State University of Campinas - UNICAMP, and the Center of Petroleum Studies - CEPETRO for providing the permission to publish this article and the support to accomplish this work. They would like to acknowledge CMG (Computer Modelling Group Ltd.) for the software support. This work was performed with the assistance from CENAPAD/SP (National Center for High Performance Computing in São Paulo). We would like to thank Brazilian National Agency of Petroleum, Natural Gas and Biofuels - ANP ("Compromisso de Investimentos com Pesquisa e Desenvolvimento").

\section{NOMENCLATURE}

Cinj - Costs of water injection

Co - Costs of oil production

$\mathrm{Cw}$ - Costs of water production

FEI - Field economic index

G1 - Group of design variables

G2 - Group of control variables

G3 - Group of potential improvement variables

Inv $v_{\text {well }}$ - Well drilling costs

IWEI - Injector well economic index

NPV - Net present value

$N_{\text {wells }}$ - Number of wells

PWEI - Producer well economic index

$r$ - Interest rate

$R o$ - Revenue from oil production

$\#_{\text {sim }}$ - Number of simulations 


\section{REFERENCES}

Andrade Filho, A. C. B. Optimal Scheduling of Development in an Oil Field. Supri-B. Stanford University, Petroleum Engineering Department, August 1994.

Beckner, B. L.; Song, X. Field development using simulated annealing - Optimal economical well scheduling and placement.. In: SPE Annual Technical Conference and Exhibition, Society of Petroleum Engineers, SPE-30650-MS, Dallas, Texas, EUA, 1995.

Botechia, V. E. Análise de Decisão Aplicada à Injeção de Polímeros no Desenvolvimento de um Campo de Óleo Pesado. 224f. Doctorate Thesis. University of Campinas, Campinas, 2016. (in Portuguese)

Gaspar, A. T. F. S.; Barreto, C. E. A. G.; Schiozer, D. J.; Assisted process for design optimization of oil exploitation strategy. Journal of Petroleum Science and Engineering, v. 146, p. 473-488, 2016. https://doi.org/10.1016/i.petrol.2016.05.042

Lamas, L. F. Comparação entre Estratégias de Produção para Projetos de Injeção de Água e de Polímeros. 132f. MSc Dissertation. University of Campinas, Campinas, 2014. (in Portuguese)
Lamas, L. F.; Schiozer, D. J. Comparison of number and position of wells for water and polymer flooding projects. International Journal of Modeling and Simulation for Petroleum Industry, v. 9(2), p. 33-40, 2016.

Leeuwenburgh, O.; Chitu, A.G.; Nair, R.; Egberts, P. J. P.; Ghazaryan, L.; Feng, T.; Hustoft, L. Ensemble-based methods for well drilling sequence and time optimization under uncertainty. 15th European Conference of the Mathematics of Oil Recovery, Amsterdam, Netherlands, 29 August - 1 September, 2016. https://doi.org/10.3997/2214$\underline{4609.201601871}$

Ravagnani, A. T. S. G.; Mazo, E. O. M.; Schiozer, D. J. A case study of the structure of the process for production strategy selection. International Journal of Modeling and Simulation for the Petroleum Industry, v. 4 (1), p. 9 - 15, 2011.

Schiozer, D. J.; Santos, A. S. S.; Drumond, P. S. Integrated model based decision analysis in twelve steps applied to petroleum fields development and management. EUROPEC, Society of Petroleum Engineers, SPE-174370-MS, Madrid, Spain, 1-4 June 2015. https://doi.org/10.2118/174370-MS 